\title{
Pengaruh Model Circuit Learning (CL) Terhadap Hasil Belajar Siswa pada Mata Pelajaran IPS
}

\author{
Siti Fatimah Dwi Husadati ${ }^{*}$, Veryliana Purnamasari ${ }^{2}$, Ibnu Fatkhu Royana ${ }^{3}$
}

12 Program Studi Pendidikan Guru Sekolah Dasar, FIP, Universitas PGRI Semarang

${ }^{3}$ Program Studi Pendidikan Jasmani Kesehatan dan Rekreasi, FPIPSKR, Universitas PGRI Semarang

\author{
ARTICLEINFO \\ Article history: \\ Received 18 May 2019 \\ Received in revised form \\ 30 June 2019 \\ Accepted 15 July 2019 \\ Available online 30 August \\ 2019 \\ Kata Kunci: \\ Model Circuit Learning (CL), \\ Hasil Belajar, Mata \\ Pelajaran IPS \\ Keywords: \\ Circuit Learning (CL), \\ Model, Learning Outcomes, \\ IPS Subject.
}

\begin{abstract}
A B S T R A K
Latar belakang yang mendasari penelitian ini adalah hasil belajar ulangan IPS masih dibawah KKM, yaitu dengan rata-rata 63 sehingga belum memenuhi ketuntasan 65 . Hal tersebut disebabkan karena guru hanya mengunakan pendekatan Teacher Centered sehingga saat proses pembelajaran siswa belum terlihat aktif. Dari permasalahan yang ada maka diperlukan model pembelajaran yang inovatif yang mengutamakan guru sebagai fasilitator, diantaranya model Circuit Learning $(\mathrm{CL})$. Desain penelitian yang digunakan peneliti yaitu eksperimen dengan jenis pra-eksperimental design tipe one-group pretest-posttest design. Sampel dalam penelitian ini diambil seluruh dari populasi yaitu siswa kelas $\mathrm{V}$ yang berjumlah 43 dengan mengunakan teknik sampling Nonprobability Sampling jenis yang dipilih yaitu sampling jenuh. Teknik pengumpulan data menggunakan tes, angket, observasi dan dokumentasi. Hasil penelitian menunjukkan bahwa ratarata posttest lebih tinggi yaitu 80,3023 dibandingkan pretest sebesar 64,9302. Hal tersebut dibuktikan dari hasil uji-t dari 43 siswa diperoleh thitung $=10,3041$ serta ttabel dengan $\mathrm{db}=\mathrm{N}-1=43-1=42$, dan taraf signifikan 0,05 sebesar $=1,681$. Karena thitung $>$ ttabel yaitu 10,3041 >1,681 maka HO ditolak dan Ha diterima. Dapat disimpulkan bahwa ada pengaruh model pembelajaran Circuit Learning terhadap hasil belajar siswa pada mata pelajaran IPS kelas V SDN Plamongansari 01 Semarang.
\end{abstract}

\section{A B S T R A C T}

The bacground that underlies this research is that the repetition of IPS learning outcomes is still bellow KKM, that is with an average of 63 so that it has not fulfilled 65 completeness. This is because the teacher only uses the teacher centered approach so that when the learning process is not active the students appear. From the existing problems an innovative learning model is needed which prioritizes teachers as facilitators including circuit learning models. The research design used by researchers was an experiment with a type of pre-experimental design type one-group pretest-postest design. The sample in this study was taken all of the populations, namely class $V$ students which numbered 43 by using the selected nonprobability sampling technique, namely satured sampling. The technique of collecting data uses test, observation, and documentation. The result showed that the postest average was higher at 80,3023 compared to pretest at 64,9302 . This was evidenced from the result of the t-test of 43 student obtained tcount $=10,3041$ and ttable with $\mathrm{db}=\mathrm{N}-1=43-1=42$ and significant level 0,05 as big as $=1,681$. Because tcount $>$ ttable $10,3041>1,681$ then $\mathrm{H} 0$ rejected and $\mathrm{Ha}$ be accepted. It can be conluded that there is the influence of the circuit learning model on student learning outcomes in subject $\mathrm{V}$ grade SDN Plamongansari 01 Semarang.

\footnotetext{
${ }^{1}$ Corresponding author.

E-mail addresses: Fatimahdwi211@gmail.com (Siti Fatimah Dwi Husadati)
} 


\section{Pendahuluan}

Pendidikan adalah salah satu cara membentuk Sumber Daya Manusia (SDM) yang berkualitas dan bermutu tinggi. Pendidikan tidak hanya mengajarkan pengetahuan dan keterampilan saja tetapi membentuk siswa menjadi manusia yang berkarakter dan bertingkah laku baik sesuai nilai-nilai yang ada di masyarakat. Pendidikan bertujuan mengembangkan kepribadian agar menjadi manusia yang dewasa dan mandiri (Soegeng, 2018:68). Pendidikan dapat memajukan suatu negara apabila proses pendidikan bisa berhasil membentuk manusia yang unggul dan berkualitas tinggi baik secara pribadi maupun sosial. Berdasarkan Undang-Undang Nomor 20 Tahun 2003 tentang Sistem Pendidikan Nasional, Ketentuan Umum pada Bab 1, Pasal 1, angka 1 menyatakan sebagai berikut:

Pendidikan adalah usaha sadar dan terencana untuk mewujudkan suasana belajar dan proses pembelajaran agar peserta didik secara aktif mengembangkan potensi dirinya untuk memiliki kekuatan spiritual keagamaan, pengendalian diri, kepribadian, kecerdasan, akhlak mulia, serta keterampilan yang diperlukan dirinya, masyarakat, bangsa dan negara.

Pendidikan tidak bisa lepas dari proses pembelajaran karena pendidikan adalah bagian dari pembelajaran (Soegeng, 2018:72). Kegiatan pembelajaran di rancang oleh guru agar siswa dapat belajar mengembangkan keterampilanya. Pembelajaran sebagai kombinasi yang tersusun, meliputi unsur manusia, material, fasilitas, perlengkapan dan prosedur yang saling mempengaruhi untuk mencapai tujuan pembelajaran (Hamalik dalam Rusman, 2017:85).

Proses pembelajaran merupakan interaksi antara guru dan siswa. Guru berperan penting dalam proses pembelajaran karena selain mengajarkan ilmu pengetahuan guru juga mendidik siswa menjadi manusia yang berkarakter baik. Mengajar dalam konteks standar pendidikan tidak hanya sekedar menyampaikan materi pelajaran, akan tetapi dimaknai sebagai proses mengatur lingkungan supaya siswa belajar. Pengaturan lingkungan adalah proses menciptakan iklim yang baik, seperti penataan lingkungan, penyedian alat dan sumber pembelajaran, dan hal-hal lain yang memungkinkan siswa betah dan merasa senang belajar sehingga mereka dapat berkembang secara optimal sesuai dengan bakat, minat, potensi yang dimilikinya (Rusman, 2017:87). Pembelajaran pada umumnya guru megarahkan siswa untuk belajar dan siswa bisa belajar menyerap makna yang telah dipelajari.

Menurut Slameto (2010:2) pengertian belajar, sebagai berikut: "belajar adalah sebuah proses usaha yang dilakukan seseorang untuk memperoleh suatu perubahan tingkah laku yang baru secara keseluruhan, sebagai hasil pengamalanya sendiri dalam interaksi dengan lingkunganya". Belajar merupakan sebuah proses untuk melatih keterampilan, pengetahuan dan sikap siswa menjadi lebih baik dari sebelum belajar. Proses belajar akan mengalami perubahan kearah yang lebih baik karena belajar dari pengalaman yang telah dilakukan.

Belajar harus ada hasil yang ingin dicapai untuk mengetahui pemahaman siswa pada materi yang dipelajari. Penilaian hasil belajar adalah proses pemberian nilai terhadap hasil-hasil belajar yang dicapai siswa dengan kriteria tertentu" (Sudjana, 2014:3). Penilaian hasil belajar dengan menilai kemampuan siswa baik lisan maupun tulis yang sifatnya menguji pemahaman yang telah dipelajari. Hasil belajar berupa data nilai yang sudah dikerjakan sesuai kemampuan yang dimiliki kemudian dievaluasi oleh guru.

Hasil penilaian tidak hanya bermanfaat untuk mengetahui tercapai atau tidaknya tujuan instruksional, dalam hal perubahan tingkah laku siswa tetapi juga sebagai umpan balik untuk memperbaiki proses belajar mengajar (Sudjana, 2014:2). Hasil belajar adalah sejumlah pengalaman yang diperoleh siswa yang mencakup ranah kognitif, afektif dan psikomotik. Ranah kognitif (pengetahuan) berkaitan untuk menguji pemahaman siswa terhadap konsep materi yang dipelajari. Ranah Psikomotor (keterampilan) adalah penilaian kegiatan fisik seperti di praktik. Ranah afektif (sikap) adalah penilaian perilaku untuk membentuk karakter yang baik, apabila sudah baik perlu di ditingkatkan lagi oleh guru.

Berdasarkan hasil observasi yang dilakukan penulis pada tanggal 4 Oktober 2018 di kelas V SD Negeri Plamongansari 01 Semarang menemukan beberapa permasalahan dalam proses belajar mengajar di kelas. Guru belum menggunakan model pembelajaran yang menarik sehingga siswa tidak memperhatikan penjelasan guru. Siswa belum terlihat aktif saat proses pembelajaran. Kreativitas dan kemandirian siswa belum terlihat saat proses pembelajaran.

Berdasarkan data nilai ulangan IPS kelas V di SDN Plamongansari 01 Semarang pada materi karakteristik geografis di Indonesia, masih banyak siswa yang mendapatkan nilai di bawah Kriteria Ketuntasan Minimal (KKM). Kriteria Ketuntasan Minimal (KKM) yang diterapkan di kelas V pada mata pelajaran IPS yaitu 65 sedangkan rata-rata nilai yang diperoleh yaitu 63. Siswa kelas V berjumlah 43 dengan nilai yang sudah tuntas $42 \%$ sedangkan $58 \%$ yang belum tuntas. Nilai 40 sampai dengan 64 didapatkan oleh 25 siswa dan nilai 65 sampai 93 didapatkan oleh 18 siswa. Hasil belajar IPS di kelas V pada materi kondisi geografis di Indonesia bisa dilihat pada tabel dibawah ini. 
Tabel 1. Data Nilai Ulangan IPS Kelas V SD N Plamongansari 01 Semarang

\begin{tabular}{ccccc}
\hline No & Nilai & Jumlah Siswa & Presentase & Keterangan \\
\hline 1 & $40-64$ & 25 & $58 \%$ & Tidak Tuntas \\
2 & $65-93$ & 18 & $42 \%$ & Tuntas \\
& Jumlah & 43 & $100 \%$ & \\
\hline
\end{tabular}

Berdasarkan uraian diatas, hasil belajar ulangan IPS kelas V SDN Plamongansari 01 Semarang ratarata dibawah KKM. Menurut peneliti perlu ada solusi untuk memecahkan masalah tersebut. Solusi yang ingin peneliti terapkan yaitu dengan adanya inovasi dalam pengunaan model pembelajaran. Model pembelajaran merupakan suatu strategi yang dipilih guru untuk menciptakan proses pembelajaran yang efektif dan menyenangkan. Setiap model pembelajaran tidak ada yang terbaik karena memiliki kelebihan dan kelemahan. Pemilihan model harus disesuaikan dengan materi dan kondisi kelas yang akan diajarkan.

Model pembelajaran yang peneliti terapkan di SDN Plamongansari 01 Semarang yaitu model cooperatif learning karena kegiatan belajar yang dilakukan dalam kelompok yang anggotanya bisa lebih dari satu orang. Siswa dilatih bekerjasama dalam kelompok untuk menyelesaikan tugas yang diberikan guru. Sanjaya dalam Rusman (2017:295) mengatakan "cooperative learning merupakan kegiatan belajar siswa yang dilakukan dengan cara berkelompok. Model pembelajaran kelompok adalah rangkaian kegiatan belajar yang dilakukan oleh siswa dalam kelompok-kelompok tertentu untuk mencapai tujuan pembelajaran yang telah dirumuskan".

Model cooperatif learning salah satunya terdapat model Circuit Learning (CL). Menurut Huda (2013:311) model Circuit Learning (CL), sebagai berikut: Circuit Learning merupakan strategi pembelajaran yang memaksimalkan pemberdayaan pikiran dan perasaan dengan pola penambahan (adding) dan pengulangan (repetition). Strategi ini biasanya dimulai dari tanya jawab tentang topik yang dipelajari, penyajian peta konsep, penjelasan mengenai peta konsep, pembagian dalam beberapa kelompok, pengisian lembar kerja siswa disertai dengan peta konsep, penjelasan tentang tata cara pengisian, pelaksanaan presentasi kelompok, dan pemberian reward atau pujian.

Kelebihan model circuit learning menurut Huda (2013:313) yaitu "meningkatkan kreativitas siswa dalam merangkai kata dengan bahasa sendiri dan melatih konsentrasi siswa untuk fokus pada peta konsep yang disajikan guru". Kekurangan model circuit learning menurut Huda (2013:313) yaitu "penerapan strategi tersebut memerlukan waktu lama dan tidak semua pokok bahasan bisa disajikan melalui strategi ini".

Berdasarkan permasalahan yang telah diuraikan diatas penulis ingin melakukan penelitian untuk mengetahui Pengaruh Model Circuit Learning (CL) Terhadap Hasil Belajar Siswa Pada Mata Pelajaran IPS Kelas V SD Negeri Plamongansari 01 Semarang.

\section{Metode}

Desain penelitian yang digunakan peneliti yaitu eksperimen dengan jenis pra-eksperimental tipe one-group pretest-posttest design yaitu hanya menggunakn satu kelas untuk penelitian. Desain ini terdapat perbandingan nilai Pretest sebelum diberi perlakuan dan nilai postest sesudah diberi perlakuan. Populasi dalam penelitian ini adalah adalah seluruh siswa kelas V SDN Plamongansari 01 Semarang Tahun Ajaran 2018/2019. Sampel dalam penelitian ini diambil seluruh dari populasi yaitu siswa kelas V yang berjumlah 43 dengan sampling yang digunakan peneliti yaitu Nonprobability Sampling jenis yang dipilih yaitu sampling jenuh.

Penelitian ini dilakukan pada bulan Mei, pada tanggal 9 Mei sampai dengan 14 Mei 2019 Semester II tahun ajaran 2018/2019. Tempat penelitian di SDN Plamongansari 01 Semarang, Jl Brigjen Sudiarto Km.11, Kecamatan Pedurungan, Kabupaten Kota Semarang, Provinsi Jawa Tengah. Peneliti sebelum melakukan penelitian melakukan studi pendahuluan untuk mencari permasalahan yang ada di SDN Plamongansari 01 Semarang. Peneliti membawa intrumen berupa lembar observasi, soal dan juga dokumentasi.

Setelah melakukan studi pendahuluan peneliti membuat proposal dan instrumen. Kemudian melakukan Uji Coba soal di SDN Rejosari 02 Semarang karena di SDN Plamongansari 01 Semarang hanya terdapat satu kelas V, jadi Uji Cobanya diluar sekolah yang di teliti oleh peneliti. Setelah Uji coba soal kemudian di analisis Validitas, Reliabilitas, Daya pembeda dan Taraf kesukaran soal menggunakan program Microsoft Exel. Dari 45 soal pilihan ganda yang diuji cobakan ada 26 soal yang valid yang nantinya digunakan untuk penelitian.

Sebelum memberikan perlakuan siswa diberikan pretest untuk mengukur kemampuan awal pada ranah kognitif. Setelah itu di beri perlakuan 2 pertemuan dengan menggunakan model Circuit Learning. 
Kemudian setelah itu posttest dengan membagikan soal yang sama seperti Pretest untuk mengukur setelah di beri perlakuan

\section{Hasil dan Pembahasan}

1. Deskripsi Data

a. Data Pretest

Data pretest memberikan gambaran kemampuan awal siswa sebelum memperoleh materi pelajaran. Nilai pretest dinyatakan tuntas jika memenuhi Kriteria Ketuntasan Minimal (KKM). Adapun KKM mata pelajaran IPS kelas V SDN Plamongansari 01 Semarang yaitu 65. Dapat dilihat pada tabel dibawah ini:

Tabel 2 Rekapitulasi Nilai Pretest

\begin{tabular}{cccccc}
\hline Jumlah Siswa & Rata-Rata & Nilai Tertinggi & Nilai Terendah & $\begin{array}{l}\text { Tuntas } \\
\text { (siswa) }\end{array}$ & Tidak Tuntas (Siswa) \\
\hline 43 & 64,9302 & 88 & 42 & 21 & 22 \\
\hline
\end{tabular}

Sumber: Data Hasil Penelitian 2019

Berdasarkan Tabel 2 di atas bahwa dari 43 siswa rata-rata yang diperoleh siswa saat pretest adalah 64,9302. Nilai tertinggi 88 dan nilai terendah 42. Sebanyak 21 siswa dinyatakan tuntas dan sebanyak 22 siswa dinyatakan tidak tuntas karena kurang mencapai batas Kriteria Ketuntasan Minimal (KKM) yaitu 65. Jadi lebih banyak siswa yang tidak tuntas pada Prettest sebelum pembelajaran mengunakan model Circuit Learning.

\section{b. Data Posttest}

Data posttest memberikan gambaran kemampuan akhir siswa sesudah memperoleh materi pelajaran (perlakuan). Nilai postest dinyatakan tuntas jika memenuhi Kriteria Ketuntasan Minimal (KKM). Adapun KKM mata pelajaran IPS kelas V SDN Plamongansari 01 Semarang yaitu 65. Data Posttest dieroleh dari tes yang sama seperti Pretest. Dapat dilihat pada Tabel dibawah ini:

Tabel 3. Rekapitulasi Hasil Nilai Posttest

\begin{tabular}{cccccc}
\hline Jumlah Siswa & Rata-Rata & Nilai Tertinggi & Nilai Terendah & $\begin{array}{c}\text { Tuntas } \\
\text { (siswa) }\end{array}$ & $\begin{array}{l}\text { Tidak Tuntas } \\
\text { (Siswa) }\end{array}$ \\
\hline 43 & 80,3023 & 96 & 46 & 41 & 2 \\
\hline & & & & Sumber: Data Hasil Penelitian 2019
\end{tabular}

Dari Tabel 3 diperoleh bahwa seluruh siswa kelas V hampir mencapai ketuntasan dengan rata-rata posttest adalah 80,3023. Nilai tertinggi 96 dan nilai terendah 46. Sebanyak 41 siswa dinyatakan tuntas dan sebanyak 2 siswa dinyatakan tidak tuntas dalam mencapai batas Kriteria Ketuntasan Minimal (KKM) yaitu 65 dari jumlah siswa 43. Data posttest nilai siswa meningkat dibandingkan nilai yang didapat pada saat prettest. Rata-rata nilai Pretest 64,9302 sedangkan rata-rata nilai Posttest 80,3023, sehingga terjadi peningkatan hasil belajar siswa setelah di beri perlakuan menggunakan model Circuit Learning. Lebih jelasnya dapat dilihat pada gambar diagram batang prettest dan posttest di bawah ini: 


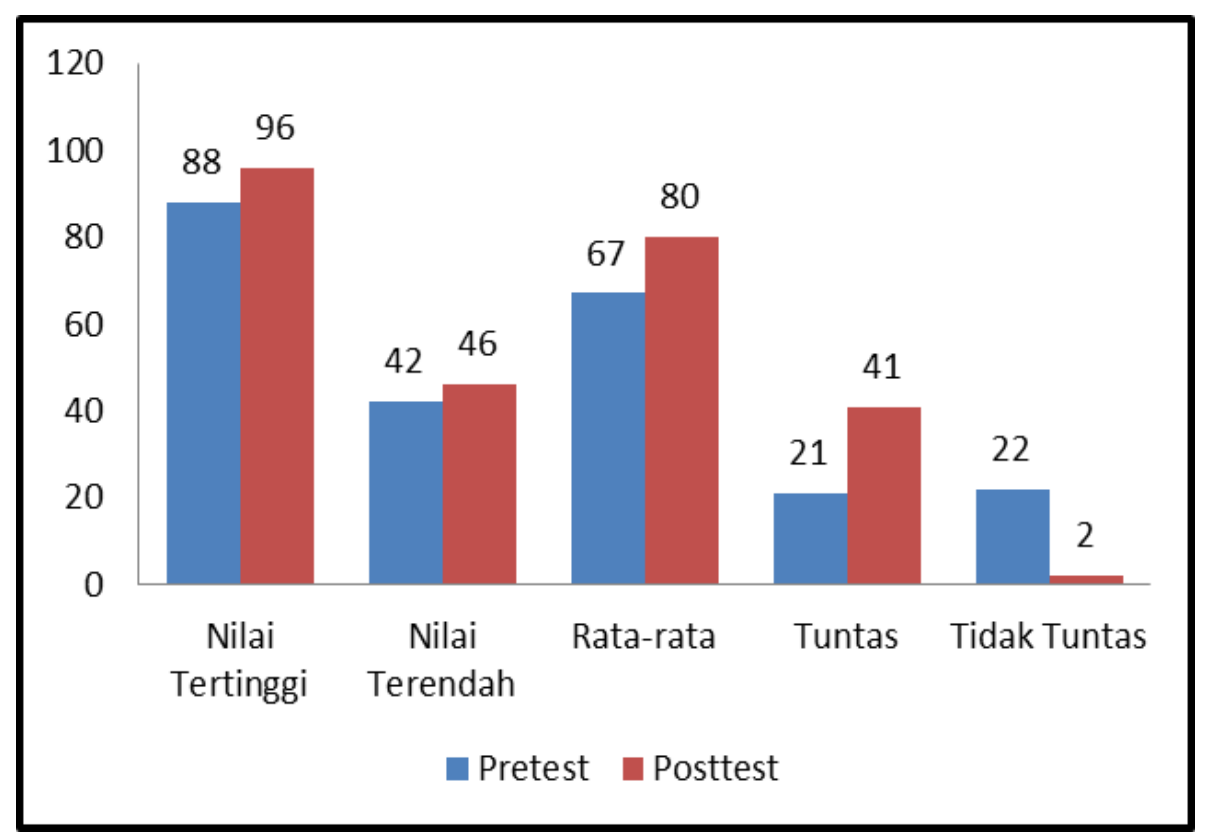

Gambar Diagram Batang Rekapitulasi Pretest dan Posttest

Berdasarkan gambar diagram batang nilai pretest dan posttest dapat dilihat bahwa terdapat perbedaan antara hasil sebelum di beri perlakuan dan sesudah diberi perlakuan mengunakan model Circuit Learning. Selanjutnya dari hasil tersebut dapat di simpulkan bahwa nilai rata-rata posttest lebih tinggi dari pada nilai rata-rata pretest.

\section{Uji Persyaratan Analisis}

Uji persyaratan analisis menggunakan uji normalitas dilakukan untuk menguji apakah sampel berasal dari populasi berdistribusi normal atau tidak. Uji yang digunkan adalah uji Liliefors (Sudjana, 2002:466-467). Hipotesinya sebagai berikut:

$\mathrm{H}_{0}$ : sampel berasal dari populasi berdistribusi normal.

Ha : sampel berasal dari populasi berdistribusi tidak normal.

Jika $\mathrm{L}_{0}<\mathrm{L}_{\text {tabel }}$ maka $\mathrm{H}_{0}$ diterima yaitu sampel berasal dari populasi yang berdistribusi normal. Jika $\mathrm{L}_{0}>\mathrm{L}_{\text {tabel }}$ maka $\mathrm{H}_{0}$ ditolak yaitu sampel berasal dari populasi yang berdistribusi tidak normal. Berdasarkan uji normalitas awal (Prettest) untuk $\mathrm{n}=43$ dan taraf nyata $\alpha=0,05$ hasilnya yaitu $\mathrm{L}_{0}<\mathrm{L}_{\text {tabel }}$, $0,1142<0,1351$. Dan uji normalitas akhir (Posttest) untuk $\mathrm{n}=43$ dan taraf nyata $\alpha=0,05$ hasilnya yaitu $\mathrm{L}_{0}<\mathrm{L}_{\text {tabel }}, 0,1146<0,1351$. Maka dapat di simpulkan bahwa $\mathrm{H}_{0}$ diterima artinya sampel Prettest dan Posttest berasal dari populasi berdistribusi normal.

\section{Uji Hipotesis}

Analisis data akhir dilakukan untuk menguji hipotesis sehingga dapat ditarik suatu kesimpulan. Adapun uji hipotesis yang digunakan dalam penelitian ini menggunakan Paired Sampel T-test untuk menguji hipotesis sebagai berikut:

1) Hipotesis nol $\left(\mathrm{H}_{0}\right)$ :

Tidak ada pengaruh model pembelajaran Circuit Learning terhadap hasil belajar siswa pada mata pelajaran IPS kelas V SDN Plamongansari 01 Semarang.

2) Hipotesis kerja $\left(\mathrm{H}_{\mathrm{a}}\right)$ :

Ada pengaruh model pembelajaran Circuit Learning terhadap hasil belajar siswa pada mata pelajaran IPS kelas V SDN Plamongansari 01 Semarang.

Apabila $\mathrm{t}_{\text {hitung }}<\mathrm{t}_{\text {tabel }}$ maka hipotesis nol $\left(\mathrm{H}_{0}\right)$ ditolak artinya tidak ada perbedaan rata-rata hasil prettest dan posttest. Jika $t_{\text {hitung }}>t_{\text {tabel }}$ maka hipotesis alternatif diterima, artinya ada perbedaan rata-rata hasil prettest dan posttest. Data yang diperoleh dari hasil hasil belajar siswa sebelum di beri perlakuan dan sesudah diberi perlakuan. Data hasil uji t dapat dilihat pada tabel dibawah ini: 
Tabel 4. Rekapitulasi Uji Hipotesis

\begin{tabular}{ccccc}
\hline Subjek & Hasil Belajar & Rata-Rata & $\mathrm{t}_{\text {hitug }}$ & $\mathrm{t}_{\text {tabel }}$ \\
\hline Kelas V SDN Plamongansari 01 & Prettest & 64,9302 & 10,3041 & 1,681 \\
Semarang & Posttest & 80,30233 & & \\
\hline
\end{tabular}

Berdasarkan hasil perhitungan diatas dari 43 siswa diperoleh $t_{\text {hitung }}=10,3041$ serta $t_{\text {tabel }}$ dengan $\mathrm{db}$ $=\mathrm{N}-1=43-1=42$, dan taraf signifikan 0,05 sebesar $=1,681$. Karena $t_{\text {hitung }}>t_{\text {tabel }}$ yaitu 10,3041 $>1,681$ maka $\mathrm{H}_{0}$ ditolak dan $\mathrm{H}_{a}$ diterima. Dapat disimpulkan bahwa ada pengaruh model pembelajaran Circuit Learning terhadap hasil belajar siswa pada mata pelajaran IPS kelas V SDN Plamongansari 01 Semarang.

Berdasarkan tahapan perkembangan kognitif Piaget bahwa anak SD berada pada tahapan operasional konkrit yaitu usia 7-11 tahun. Dalam tahap ini siswa mampu berpikir secara logis dan mampu memecahkan masalah. Hal ini sejalan dengan kemampuan siswa dalam memilih dan memecahkan berbagai masalah dengan berpikir logis. Dan Teori belajar Vygotsky ini sesuai dengan penelitian ini karena model Circuit Learning menekankan pada aspek sosial dari pembelajaran atau belajar kelompok. Melalui belajar kelompok ini siswa dapat menangani tugas-tugas yang diberikan dan dapat memberikan bantuan kepada temannya yang belum menguasai materi yang diberikan.

Dari data hasil belajar pretest diperoleh nilai rata-rata 64,9302. Nilai tertinggi 88 dan nilai terendah 42. Sebanyak 21 siswa dinyatakan tuntas dan sebanyak 22 siswa dinyatakan tidak tuntas karena kurang mencapai batas Kriteria Ketuntasan Minimal (KKM) yaitu 65. Setelah di berikan perlakuan kemudian dilakukan posttest di peroleh nilai rata-rata 80,30233. Nilai tertinggi 96 dan nilai terendah 46. Sebanyak 41 siswa dinyatakan tuntas dan sebanyak 2 siswa dinyatakan tidak tuntas dalam mencapai batas Kriteria Ketuntasan Minimal (KKM) yaitu 65 dari jumlah siswa 43. Data posttest nilai siswa meningkat dibandingkan nilai yang didapatkan siswa pada saat prettest. Rata-rata nilai Pretest 64,9302 sedangkan rata-rata nilai Posttest 80,30233. Berdasarkan nilai pretest dan posttest dapat dilihat bahwa terdapat peningkatan hasil belajar sebelum di beri perlakuan dan sesudah diberi perlakuan mengunakan model Circuit Learning.

Hasil belajar meningkat karena proses pembelajaran menggunakan model circuit learning mendukung siswa untuk aktif dalam pembelajaran. Siswa diminta untuk terlibat langsung dalam memahami pelajaran yang diberikan guru dan mengembangkan keterampilan bekerjasama antar kelompok. Hal yang sama juga disampaikan Shoimin (2017:18) bahwa model pembelajaran yang inovatif, siswa dilibatkan secara aktif dan bukan hanya dijadikan objek. Pembelajaran tidak lagi berpusat pada guru, tetapi pada siswa. Siswa dilatih bekerjasama dalam kelompok untuk menyelesaikan tugas yang diberikan guru.

Pada uji normalitas awal (Prettest) $\mathrm{L}_{0}$ sebesar 0,1142 untuk $\mathrm{n}=43$ dan taraf nyata $\alpha=0,05$. Berdasarkan nilai kritis L untuk Uji Liliefors diperoleh harga $\mathrm{L}_{\text {tabel }}=0,1351$. Hal ini menunjukan bahwa $\mathrm{L}_{0}$ $<\mathrm{L}_{\text {tabel }}, 0,1142<0,1351$ maka dapat diambil kesimpulan bahwa $\mathrm{H}_{0}$ diterima artinya sampel berasal dari populasi berdistribusi normal. Pada uji normalitas akhir (Posttest) sebesar $L_{0}$ sebesar 0,1146 untuk $n=43$ dan taraf nyata $\alpha=0,05$. Berdasarkan nilai kritis $L$ untuk uji liliefors diperoleh harga $L_{\text {tabel }}=0,1351$. Hal ini menunjukan bahwa $\mathrm{L}_{0}<\mathrm{L}_{\text {tabel }}, 0,1146<0,1351$ maka dapat diambil kesimpulan bahwa $\mathrm{H}_{0}$ diterima artinya sampel berasal dari populasi berdistribusi normal. Jadi sampel data pretest dan posttest berdistribusi normal.

Berdasarkan hasil perhitungan dengan menggunakan Uji T dari 43 siswa diperoleh $t_{\text {hitung }}=10,3041$ serta $t_{\text {tabel }}$ dengan db N-1=43-1 $=42$, dan taraf signifikan 0,05 sebesar $=1,681$. Karena $t_{\text {hitung }}>t_{\text {tabel }}$ yaitu 10,3041 >1,681 maka $\mathrm{H}_{0}$ ditolak dan $\mathrm{H}_{\mathrm{a}}$ diterima. Dapat disimpulkan bahwa Ada pengaruh model pembelajaran Circuit Learning terhadap hasil belajar siswa pada mata pelajaran IPS kelas V SDN Plamongansari 01 Semarang.

Sejalan dari penelitian yang dilakukan Pramita, Ayu (2019) Hasil penelitian ini terdapat perbedaan yang signifikan hasil belajar IPA pada kelas eksperimen yang mengunakan model pembelajaran Circuit Learning berbantuan media Flip Chart daripada Kelas kontrol dengan pembelajaran konvensional pada siswa kelas V SD di Gugus III Kecamatan Seririt Tahun Pelajaran 2017/2018. Hasil pengujian menunjukkan bahwa $t_{\text {hitung }}(7,844)$ lebih besar daripada $t_{\text {tabel }}(2,014)$ pada taraf signifikansi $5 \%$ dengan $\mathrm{db}$ $=45$ 


\section{Simpulan dan Saran}

Berdasarkan hasil analisis data dan perhitungan uji hipotesis menggunakan analisis data uji paired sample t-test, dari 43 siswa diperoleh thitung = 10,3041 serta ttabel dengan $\mathrm{db} \mathrm{N}-1=43-1=42$, dan taraf signifikan 0,05 sebesar $=1,681$. Karena thitung $>$ ttabel yaitu 10,3041>1,681 maka H0 ditolak dan Ha diterima. Dapat disimpulkan bahwa Ada pengaruh model pembelajaran Circuit Learning terhadap hasil belajar siswa pada mata pelajaran IPS kelas V SDN Plamongansari 01 Semarang.

Data posttest nilai siswa meningkat dibandingkan nilai yang didapatkan siswa pada saat prettest. Rata-rata nilai Pretest 64,9302 sedangkan rata-rata nilai Posttest 80,30233. Berdasarkan nilai pretest dan posttest maka terdapat peningkatan sebelum di beri perlakuan dan sesudah diberi perlakuan mengunakan model Circuit Learning. Saran-saran yang kami sampaikan sehubunggan dengan hasil penelitian ini: 1. Guru dapat menggunakan model pembelajaran circuit learning sebagai salah satu upaya untuk meningkatkan hasil belajar siswa, dan 2. Siswa diharapkan dapat berpartisipasi aktif dalam kegiatan pembelajaran sehingga dapat menerima materi dengan mudah..

\section{Daftar Rujukan}

Arikunto, S. (2015). Dasar-Dasar Evaluasi Pendidikan Edisi 2. Jakarta: PT Bumi (Budiningsih, 2008) (Nurhasanah, 2008)Aksara.

Arikunto, S. (2010). Prosedur Penelitian Suatu Pendekatan Praktik. Jakarta: PT Rineka Cipta.

Aunurrahman. (2013). Belajar dan Pembelajaran. Bandung: Alfabeta.

Budiningsih, A. (2008). Belajar dan Pembelajaran. Jakarta: PT Rineka Cipta.

Departemen Pendidikan Nasional. (2003). Undang-Undang Repuplik Indonesia Nomor 20 Tahun 2003 tentang Sistem Pendidikan Nasional Bab 1 Ketentuan Umum Pasal 1. Jakarta: Depdiknas.

Emzir. (2014). Metodologi Penelitian Pendidikan Kuantitatif dan Kualitatif. Jakarta: PT Rajagrafindo Persada.

Fitri, R. (2018). Penerapan Model Pembelajaran Circuit Learning terhadap Kemampuan Komunikasi Matematis Siswa Kelas X SMA N 1 Pasir Penyu. Jurnal Mathematic Education and Science, Vol 4 No 1.

Huda, M. (2017). Cooperative Learning. yogyakarta: Pustaka Pelajar.

Huda, M. (2013). Model-Model Pengajaran dan Pembelajaran. Yogyakarta: Pustaka Pelajar.

Mahmud. (2011). Metode Penelitian Pendidikan. Bandung: CV Pustaka Setia.

Mudjiono, D. (2010). belajar dan Faktor yang Mempengaruhinya. Jakarta: PT Rineka Cipta.

Ngalimun. (2014). Strategi dan Model Pembelajaran. Yogyakarta: Aswaja Presindo.

Paramita, A. (2019). Pengaruh Model Pembelajaran Circuit Learning Berbantuan Media Flip Chart Terhadap Hasil Belajar IPA. Jurnal Ilmiah Pendidikan Profesi Guru, Vol 2 No 1.

Permendikbud. (2016). Peraturan Mentri Pendidikan dan Kebudayaan Repuplik Indonesia Nomor 22 Tahun 2016 Standar Proses Pendidikan Dasar dan Menengah. Jakarta: Permendikbud.

Ristianingrum, R. D. (2018). Perbedaan Hasil Belajar Matematika Siswa dengan dan Tanpa Menggunakan Model Pembelajaran Kooperatif Tipe Circuit Learning Materi Bangun Ruang Kelas VIII . Jurnal Edu Math , Volume 5 Nomor 2 Halaman 24-29.

Rusman. (2017). Belajar dan Pembelajaran. jakarta: kencana.

Sapriya. (2014). Pendidikan IPS. Bandung: PT Remaja Rosdakarya. 
Shoimin, A. (2014). 68 Model Pembelajaran Inovatif dalam Kurikulum 2013. Yogyakarta: Ar-Ruzz Media.

Soegeng, A. (2018). Filsafat Pendidikan. Yogyakarta: Magnum Pustaka Utama.

Sudjana. (2002). Metoda Statistika. Bandung: PT Tarsito Bandung.

Sudjana, N. (2016). Penilaian Hasil Proses Belajar Mengajar. Bandung: PT Remaja Rosdakarya.

Trianto. (2011). Model-Model Pembelajaran Inovatif Berorientasi Kontruktivistik. Jakarta: Prestasi Pustaka Publisher. 